\title{
Coexisting multiple myeloma, lymphoma, and non- small cell lung cancer: a case report and review of the literature
}

\author{
Parth Khade \\ Srinivas Devarakonda \\ Department of Internal Medicine, \\ Louisiana State University Health, \\ Shreveport, LA, USA
}

This article was published in the following Dove Press journal:

International Medical Case Reports Journal

8 November 2017

Number of times this article has been viewed

\begin{abstract}
Multiple myeloma is a plasma cell dyscrasia characterized by neoplastic proliferation of plasma cells, producing a monoclonal immunoglobulin. Small lymphocytic lymphoma (SLL) is a neoplasm consisting of monoclonal B-cell lymphocyte proliferation. We present an extremely rare case of coexisting multiple myeloma, SLL, and squamous cell carcinoma of the lung in a 74-year-old female patient. She initially presented with a midline mass with pain in the lumbar area. Debulking surgery was performed, and pathology showed plasmacytoma. Further evaluation revealed coexistent IgG kappa myeloma. Imaging revealed extensive abdominal lymphadenopathy, and mesenteric lymph node biopsy confirmed the presence of SLL. The patient was also found to have a mass in the left lower lobe of the lung; biopsy showed squamous cell carcinoma. This patient was treated with lenalidomide and dexamethasone for multiple myeloma, and stereotactic body radiotherapy for limited stage lung cancer. Due to the more indolent course of SLL, watchful waiting was applied.
\end{abstract}

Keywords: coexisting, multiple myeloma, lung cancer, non-Hodgkin's lymphoma

\section{Background}

Multiple myeloma is a plasma cell dyscrasia characterized by neoplastic proliferation of plasma cells secreting a monoclonal immunoglobulin. The majority of patients present with a monoclonal M-protein produced by the plasma cells, which is detected by serum protein electrophoresis. ${ }^{1}$ The diagnosis of active multiple myeloma as established by the International Myeloma Working Group criteria ${ }^{2}$ requires: clonal bone marrow plasma cells $\geq 10 \%$ or biopsy-proven bony or extramedullary plasmacytoma plus either the presence of related organ or tissue impairment (anemia, hypercalcemia, renal insufficiency, and bone lesions) or myeloma-defining events ( $60 \%$ or greater clonal plasma cells on bone marrow examination, serum involved/uninvolved free light chain ratio of 100 or greater, or more than one focal lesion on magnetic resonance imaging [MRI] that is at least $5 \mathrm{~mm}$ or greater in size). Malignant plasma cells uniformly overexpress CD38, CD138, and CD56 molecules. Alterations in these signaling molecules and other cytokines play a key role in the pathophysiologic mechanism of multiple myeloma. In the USA, there are an estimated number of approximately 30,000 new cases of multiple myeloma expected for the year 2017, with an estimated $\sim 12,600$ deaths. ${ }^{3}$ Small lymphocytic lymphoma (SLL) is a mature, peripheral B-cell neoplasm characterized by monoclonal proliferation of small lymphocytes, leading to lymphadenopathy with or without organomegaly and extranodal infiltrates. Diagnosis is made by excisional lymph node biopsy along with bone marrow biopsy and aspirate. Lung cancer is the

Correspondence: Srinivas Devarakonda Department of Internal Medicine, Louisiana State University Health, I50 I Kings Highway, Shreveport, LA 7II 30, USA

Email sdeva I@Isuhsc.edu 
most common cancer worldwide, and among non-small cell variants, squamous cell variant ranks next to adenocarcinoma in frequency. It is usually diagnosed upon evaluation for symptoms suggestive of lung cancer or an incidental lesion found on imaging. A definitive diagnosis with pathology is made with tissue biopsy of one of the suspicious lesions. There are a few documented cases reporting coexisting multiple myeloma and non-Hodgkin's lymphoma (NHL); ${ }^{4}$ in this case report, we present an extremely rare case of coexisting multiple myeloma, SLL, and squamous cell carcinoma of the lung.

\section{Case presentation}

Our patient is a 74-year-old female with a past medical history of type 2 diabetes mellitus, hypertension, known cervical dysplasia status post total abdominal hysterectomy and bilateral salpingo-oophorectomy, and significant tobacco use who presented with a complaint of a painful midline mass in the lumbar area measuring $5 \mathrm{~cm} \times 3 \mathrm{~cm}$ on examination. It was firm, fixed with diffuse margins, and tender to palpation. The patient did not experience any neurological symptoms such as focal weakness, numbness, or incontinence. Written informed consent has been provided by the patient to have the details of her case published.

\section{Investigations}

MRI of lumbar spine was obtained, which revealed a prominent infiltrate in the posterior aspect of the spinal canal involving the spinous processes from L2/L3 to L3/L4 measuring $6 \mathrm{~cm} \times 5 \mathrm{~cm}$, reaching the muscular fascia, and another infiltrate at the L1 vertebral body. No evidence of thecal sac compression was noted. A chest radiograph was performed as part of preoperative evaluation, which revealed a spiculated mass in the lower lobe of the left lung. Computed tomography (CT) of the chest, abdomen, and pelvis was performed for further evaluation, which revealed a left lung lower lobe mass measuring $2.4 \mathrm{~cm}$. Multiple lytic lesions in the right scapula, right ribcage, and vertebral bodies were also seen. Extensive intraperitoneal, retroperitoneal, and pelvic sidewall lymphadenopathy was seen on abdominal imaging. Multiple areas of enlarged lymph nodes were seen in the mesentery (largest measuring $2.8 \mathrm{~cm})$, bilateral axillae $(1.3 \mathrm{~cm}$ in right axilla), and hepatic hilum (largest measuring $6.8 \mathrm{~cm}$ ). The patient was noted to have a protein gap with total serum protein of $8.4 \mathrm{~g} / \mathrm{dL}$ and serum albumin of $2.9 \mathrm{~g} / \mathrm{dL}$.

She underwent debulking of the lumbar mass with significant relief from back pain. Pathological review showed the lumbar mass to be plasmacytoma, and immunohistochemical staining was positive for CD138 and CD56. Kappa and lambda light chain in situ hybridization showed monoclonal expression of kappa light chain in the neoplastic cells. Serum protein electrophoresis with immunofixation revealed an M-protein of $3.5 \mathrm{~g} / \mathrm{dL}$ with kappa light chain restriction. Kappa/lambda ratio was noted to be elevated at 20.7, and total IgG was elevated at $2930 \mathrm{mg} / \mathrm{dL}$. Urine protein electrophoresis with immunofixation also showed the presence of monoclonal protein.

Computed tomography (CT)-guided biopsy of the left lung mass and axillary lymph nodes was positive for moderately differentiated squamous cell carcinoma. Immunostaining was positive for P40 and negative for TTF1. Biopsy of one of the mesenteric lymph nodes was positive for SLL. The lymph node showed a partially effaced architecture with sheets of small lymphocytes that stained positive for CD20, PAX-5, CD79a, CD23, and CD5 and negative for CD56, CD138, and cyclin D1.

It is uncommon for carcinoma of the lung to metastasize to the mesenteric and pelvic lymph nodes, and so surgical biopsy of mesenteric lymph nodes was performed which revealed SLL.

\section{Treatment}

The workup mentioned earlier revealed that there were three coexisting malignancies - multiple myeloma (stage II, IgG kappa), stage I moderately differentiated squamous cell carcinoma of the left lower lobe of the lung, and SLL. At the time of diagnosis, the patient had an Eastern Cooperative Oncology Group (ECOG) performance status of 2.

Due to the more indolent course of SLL, we opted to do watchful waiting. The patient underwent stereotactic body radiation therapy (SBRT) for the early-stage lung cancer with curative intent. She was started on a regimen consisting of lenalidomide and low-dose dexamethasone ( $\mathrm{Rd})$, with the dosage of both drugs adjusted for her old age. She was also started on bisphosphonates with dose adjustment for her renal function.

\section{Outcome and follow-up}

At the last clinic visit, 4 months after initiating treatment, the patient had an ECOG performance status of 1 . She achieved very good partial response (VGPR) after four cycles of $\mathrm{Rd}$ for her myeloma. She denied any skeletal pain or treatmentrelated toxicity. She was asymptomatic from her lymphoma, and lung cancer was in remission. We decided that she is not a candidate for autologous stem cell transplant in view of her age and other comorbidities and opted to continue treatment with chemotherapy until progression or toxicity.

\section{Discussion}

Concomitant multiple myeloma, SLL, and squamous cell carcinoma of the lung is extremely rare. Studies have 
shown multiple primary malignant tumors (MPMTs) to be most commonly seen with tumors of the head and neck ${ }^{5}$ as well as in the digestive system. ${ }^{6}$ A recent clinical analysis of 152 cases of MPMTs in 15,398 patients with malignant tumors by Liu et $\mathrm{l}^{5}$ revealed an incidence of $0.99 \%$, with 51 cases documented as synchronous MPMTs, and 101 cases documented as metachronous MPMTs. In this case report, there were no documented cases of MPMTs in 404 cases of multiple myeloma.

To date, there are few cases (to our knowledge, less than 100 total cases) documenting the presence of coincident multiple myeloma and NHL., ${ }^{4-19}$ There are multiple cases documenting multiple myeloma with coexisting solid tumor neoplasms $;{ }^{20}$ however, to our knowledge, this is the first case report documenting the presence of multiple myeloma, NHL, and a third concurrent primary malignancy, specifically nonsmall cell lung cancer (NSCLC).

Hasskarl et $\mathrm{al}^{20}$ documented 589 patients with multiple myeloma, of whom 59 patients had coexisting primary neoplasms. From these 59 patients, $46(72 \%)$ had associated solid tumors and $13(22 \%)$ had hematological neoplasms. Eight out of 59 patients had two additional neoplasms documented in addition to multiple myeloma, and out of these eight patients, only two had coexisting multiple myeloma and NHL, in addition to a third primary neoplasm (one case with prostate cancer, and the other with acute myeloid leukemia [AML]).

Multiple myeloma is a malignancy involving the neoplastic proliferation of plasma cells leading to the production of a monoclonal immunoglobulin, either in the serum or the urine or more commonly both. SLL is a neoplasm consisting of monoclonal B-cell lymphocyte proliferation. In our index case, the diagnostic criteria for multiple myeloma were fulfilled by IgG kappa monoclonal gammopathy with lytic bone lesions, while mesenteric lymph node biopsy confirmed the presence of SLL.

It has been discussed in previous reports ${ }^{4}$ that coexisting multiple myeloma and NHL may arise from pathogenetic transformation of lymphoma cells into plasma cells. Due to the rarity of coexisting malignancies such as this, it is also important to consider where to focus treatment efforts. In our index case, active therapy was directed against multiple myeloma, due to the risk posed by development of lumbar plasmacytoma and other lytic bone lesions.

\section{Disclosure}

The authors report no conflicts of interest in this work.

\section{References}

1. Kyle RA, Gertz MA, Witzig TE, et al. Review of 1027 patients with newly diagnosed multiple myeloma. Mayo Clin Proc. 2003;78(1):21-33.

2. Rajkumar SV, Dimopoulos MA, Palumbo A, et al. International myeloma working group updated criteria for the diagnosis of multiple myeloma. Lancet Oncol. 2014;15(12):e538-e548.

3. Siegel RL, Miller KD, Jemal A. Cancer statistics, 2017. CA Cancer J Clin. 2017;67(1):7-30.

4. Lee GC, Hong JS, Lee KH, et al. A case of coincident multiple myeloma and non-Hodgkin's lymphoma. Korean J Intern Med. 1994;9(2):113-115.

5. Liu Z, Liu C, Guo W, Li S, Bai O. Clinical analysis of 152 cases of multiple primary malignant tumors in 15,398 patients with malignant tumors. PLoS One. 2015;10(5):e0125754.

6. Lv M, Zhang X, Shen Y, et al. Clinical analysis and prognosis of synchronous and metachronous multiple primary malignant tumors. Medicine (Baltimore). 2017;96(17):e6799.

7. Manley R, Monteath J, Patton WN. Co-incidental presentation of IgA lambda multiple myeloma and pleural involvement with IgM kappa non-Hodgkin's lymphoma. Clin Lab Haematol. 1999;21(1):61-63.

8. Grau E, Soler J, Puig J, et al. Coincident multiple myeloma and nonHodgkin's lymphoma with 2 serum monoclonal immunoglobulins. Acta Haematol. 1986;75(3):183-185.

9. Brouet JC, Fermand JP, Laurent G, et al. The association of chronic lymphocytic leukaemia and multiple myeloma: a study of eleven patients. Br J Haematol. 1985;59(1):55-66.

10. Pedersen-Bjergaard J, Petersen HD, Thomsen M, Wiik A, Wolff-Jensen J. Chronic lymphocytic leukaemia with subsequent development of multiple myeloma. Evidence of two B-lymphocyte clones and of myeloma-induced suppression of secretion of an M-component and of normal immunoglobulins. Scand J Haematol. 1978;21(3):256-264.

11. Langer S, Mehta M, SarafA, et al. Concomitant presence of two distinct clones of chronic lymphocytic leukemia and plasma cell myeloma in a patient. Indian J Hematol Blood Transfus. 2016;32(suppl 1):173-177.

12. Chang H, Wechatekar A, Li L, Reece D. Molecular cytogenetic abnormalities in patients with concurrent chronic lymphocytic leukemia and multiple myeloma shown by interphase fluorescence in situ hybridization: evidence of distinct clonal origin. Cancer Genet Cytogenet. 2004;148(1):44-48.

13. Srinivasan S, Schiffer CA. Concurrent B-cell chronic lymphocytic leukemia and multiple myeloma treated successfully with lenalidomide. Leuk Res. 2009;33(4):561-564.

14. Kontozoglou T, Skinnider LF. Concurrent appearance of multiple myeloma with other B-cell lymphoid neoplasms. A report of two cases. Arch Pathol Lab Med. 1983;107(5):232-234.

15. Devi VL, Prabhash K, Malathi M, Madhumathi DS, Bapsy PP. Uncommon manifestations of common malignancies: case 2 . Chronic lymphocytic leukemia and multiple myeloma in the same patient. J Clin Oncol. 2004;22(15):3192-3193.

16. Rogulj IM, Radic-Kristo D, Milunovic V, Kolonic SO, Jelic-Puskaric B, Planinc-Peraica A. Multiple myeloma in a patient with chronic lymphocytic leukemia - case report and literature review. Acta Med Croatica. 2011;65(suppl 1):173-177.

17. Aktan M, Akkaya A, Dogan O, Dincol G. Chronic lymphocytic leukemia and multiple myeloma in the same patient: case report. Leuk Lymphoma. 2003;44(8):1421-1424.

18. Bassan R, Comotti B, Minetti B, Viero P, Barbui T. Concurrent multiple myeloma and chronic lymphocytic leukemia. Am J Clin Pathol. 1984;82(5):624-627.

19. Fermand JP, James JM, Herait P, Brouet JC. Associated chronic lymphocytic leukemia and multiple myeloma: origin from a single clone. Blood. 1985;66(2):291-293.

20. Hasskarl J, Ihorst G, De Pasquale D, et al. Association of multiple myeloma with different neoplasms: systematic analysis in consecutive patients with myeloma. Leuk Lymphoma. 2011;52(2):247-259. 
The International Medical Case Reports Journal is an international, peer-reviewed open-access journal publishing original case reports from all medical specialties. Previously unpublished medical posters are also accepted relating to any area of clinical or preclinical science. Submissions should not normally exceed 2,000 words or
4 published pages including figures, diagrams and references. The manuscript management system is completely online and includes a very quick and fair peer-review system, which is all easy to use. Visit http://www.dovepress.com/testimonials.php to read real quotes from published authors.

Submit your manuscript here: https://www.dovepress.com/international-medical-case-reports-journal-journal 